\title{
UROLOGICAL MANAGEMENT IN NON-TRAUMATIC PARAPLEGIA: DISC PROTRUSIONS, MULTIPLE SCLEROSIS AND SPINAL METASTASES
}

\author{
By R. M. Jameson, F.R.C.S., Urologist, Liverpool A.H.A.(T.) \\ Regional Paraplegic Centre, Southport Promenade Hospital and Regional Urological Centre, \\ Sefton General Hospital
}

\section{Introduction}

FROM 1967-75, I 57 cases of paraplegia and tetraplegia of non-traumatic origin were admitted. The management of the bladder dysfunction in the non-traumatic patient is similar to the care of the traumatic case, for usually the neurological lesion remains static (Ross et al., I964; Jameson, 1974). There are two important exceptions to this statement; multiple sclerosis and malignant disease. The causes of paralysis in these non-traumatic patients are shown in Table I. Bladder dysfunction is found in 80 per cent of these cases, and 20 per cent have renal complications. In the paraplegic the duration and quality of life is related to the degree of urinary tract impairment so that the urologist will find these patients present a challenge in preventing death from urinary tract disease and improving the act of disordered micturition so the patient can be rehabilitated in society. Two years ago the management of the bladder in non-traumatic paraplegia was reviewed and the principles of management discussed (Jameson, I974); I propose to illustrate some of the principles involved in the management of disc protrusions and spinal degeneration, multiple sclerosis and malignant disease.

\section{Disc Protrusions and Spinal Degeneration}

Initial reports of bladder dysfunction due to a prolapsed lumbar intervertebral disc emphasised the bladder paralysis associated with massive disc protrusion and the occult nature of the neurological symptoms and signs (Mallock, I965; Yaxley, I966; Love \& Emmett, I967; Emmett \& Love, I968 \& I97I; Cosbie Ross \& Jameson, I97I). Most of our cases had detrusor paralysis which was permanent in 19 out of 40 cases. Loss of bladder sensation was an early sign and lack of bladder inhibition was found and confirmed by cystometry by Jones and Moore (I973).

There is a spectrum of bladder dysfunction; at one extreme is the acute disc paraplegia with urinary retention needing emergency laminectomy, at the other the uninhibited irritable bladder. The bladder dysfunction, whether temporary or permanent, falls into four groups; the more severe the neural change the greater the risk of permanent bladder damage (Table II).

The Uninhibited Irritable Bladder. Credit must go to Jones and Moore for first describing this disorder in disc prolapse. Presumably it is caused by nerve root irritation. There is no residual urine and the bladder sensation is normal. Urodynamic studies will show that the bladder detrusor is uninhibited 


\section{TABLE I}

Causes of non-traumatic paraplegia in cases admitted 1967-75.

$\begin{array}{lllllr}\text { Multiple sclerosis } & 20 & \text { Disc lesions } & 25 & \text { Acute myelitis } & \text { I8 } \\ \text { Cord tumours } & \text { I6 } & \text { Vascular lesions } & \text { I7 } & \text { Spina bifida } & 8 \\ \text { Spinal metastases } & \text { I7 } & \text { Bone diseases } & \text { I8 } & \text { Other } & 8 \\ & & \text { Total }=\text { I57 cases } & & & \end{array}$

\section{TABLE II}

Bladder dysfunction in disc protrusion

\section{The uninhibited irritable bladder}

Normal visceral sensation. Detrusor uninhibited and unstable.

No residual urine. No outflow obstruction, surgery contraindicated.

Responds to amitryptilline and conservative measures to spine.

Only $7 / 22$ in this group had permament bladder irritability.

\section{Neurogenic bladder with retention}

Half have bladder irritability antedating retention.

Half have defective vesical sensation. May mimic detrusor instability associated with outflow obstruction, bladder neck or sphincter dyskinesia may be responsible. $8 / 24$ in this group had permanent dysfunction, 4 needed endoscopic surgery.

\section{Occult type}

Minimal or absent lumbar or sciatic pain. Absent bladder sensation.

Severe detrusor damage usual. Permanent bladder dysfunction in two-thirds. I 5 cases in this group.

\section{Disc paraplegia}

Dramatic onset, emergency laminectomy needed. Bladder recovery may take a year. Endoscopic surgery to reduce outflow resistance needed.

Permanent bladder dysfunction in $15 / 20$ cases.

and unstable. It is likely that this type of bladder dysfunction is commoner than at first supposed. As the patient presents with back or sciatic symptoms the urinary symptoms may only be noted on direct questioning. Characteristically the urinary symptoms disappear after bed rest on a firm mattress or after traction. In patients with degenerative spinal disorders, for example spinal stenosis, the urinary symptoms will predominate as the spinal condition is of gradual onset and the patient may tolerate gradual back stiffness but find bladder irritability distressing. Twenty-two out of a total 8I patients with neurogenic bladder disturbances associated with disc disease and spinal degeneration had this group of uninhibited bladder. Only seven out of the 22 cases had a permanent bladder irritability and five of these had severe degenerative disease of the lumbar spine. The majority respond to conservative treatment of the disc lesion, or amitryptilline, Io mgm. t.d.s. is of help. Prostatectomy or bladder-neck surgery is not indicated, as by definition there is no outflow obstruction, indeed such procedures will aggravate the symptoms. 
Neurogenic Bladder with Retention. Half of this group have an irritable bladder preceding urinary retention; the other half have loss of bladder sensation leading to retention. The former are a stage further than simply an uninhibited detrusor, indeed urethral pressure profiles in some have shown an intermittent spasm of the external sphincter. I suggest that some form of bladder neck or external sphincter dyskinesia is responsible for the retention, although not all cases have had the opportunity of complete study by the urethral pressure profile. For example, Case I in our original study (Ross \& Jameson, I97I) was a medical practitioner who had backache with sciatica for a month followed by bladder irritability for two days and severe back pain. He developed retention and at laminectomy a large disc protrusion at the 4 th/5th lumbar space was removed. He had no previous urinary symptoms.

In a similar manner Case 2 of the paper illustrated that an insidious painless retention does occur with disc prolapse. The patient was decorating his home and strained his back. To relieve the pain he went to bed and called his family doctor who found that he had also a painless urinary retention. There was perineal anaesthesia, an absent ankle jerk on the right with a weak right-knee jerk. In both these patients normal voiding was resumed after conservative treatment by bladder drainage for a few days. Fortunately the bladder disturbance is usually temporary and responds to simple treatment. Permanent bladder disturbances were found in eight out of 24 of this group. Four were associated with a minor degree of outflow obstruction which needed surgery; unfortunately the other four had a painless retention with overflow which was overlooked so that in addition to the sensory loss there was also local detrusor and sensory damage resulting from the overdistension. This damage has been described by Mayo et al. (1973). All cases in this group have deficient bladder sensation with an increasing residual urine culminating in retention. The moral to be drawn is that no patient immobilised in home or hospital should be allowed to develop urinary retention and that patients with back pain or sciatica must have an abdominal examination as well as a rectal examination.

Occult Type. This group has been well documented and is characterised by minimal or absent back and leg pain, loss of bladder sensation and often urinary retention with detrusor damage following prolonged overdistension (Love \& Emmett, I967; Emmett \& Love, I968, I97I; Ross \& Jameson, I97I.) This is a more severe lesion than in the preceding groups and frequently surgery is needed to reduce outflow resistance to enable the patient to void. In women suprapubic pressure (Crede Manoeuvre) usually enables complete emptying to be achieved, less commonly Otis urethrotomy or simple repeated urethral dilatation is needed. Half these patients had permanent bladder damage, either a weak detrusor or some sensory loss. Many of these patients are obese women and prone to recurrent back injury with subsequent bladder disturbances. When the detrusor has been affected by overdistension, outflow resistance can be lessened by endoscopic division of the external sphincter. This is particularly valuable in the severe cases and it does not, of course, make the patient incontinent. In some cases the bladder is so insensitive and atonic that there is great difficulty in reducing resistance to enable the patient to void; one patient needed a permanent indwelling catheter. 
Disc Paraplegia. This group is the most severe type of bladder dysfunction, usually of acute and dramatic onset with paraplegia with retention. Emergency laminectomy is required and, however prompt and skilled the surgery, bladder recovery will take at least a year. Bladder sensation is the first to recover after several months and the detrusor is commonly weakened so that suprapubic pressure or endoscopic surgery is necessary to ensure complete bladder emptying. Combined resection of the bladder neck and external sphincter may be indicated to reduce outflow resistance. Although this is the extreme end of the spectrum of bladder dsyfunction due to degenerative and disc disease of the spine only five out of 20 cases of disc paraplegia had permanent bladder damage; the rest had normal voiding and cystometrograms within two years of the disc paraplegia.

There is no constant relationship between the level of the neurological lesion and the nature or severity of bladder dysfunction; nevertheless, in our 8I cases some trends appear. Single nerve root lesions rarely produce bladder dysfunction unless there is spinal stenosis or gross spinal deformity or degeneration. High spinal lesions either produce an uninhibited bladder with urgency or an upper motor neurone bladder, often with bladder outlet dyskinesia needing sphincter resection or, more recently, medication to relieve hypertonicity of the external sphincter area. Upper lumbar disc lesions can produce bladder dysfunction of any type and it is not possible to predict the seriousness or permance of the bladder dysfunction from the level of a lumbar disc lesion. Gangai (1966) found that bladder disturbances were found in 3.5 per cent of disc protrusions. My impression, based upon selective referral to the Urological or Paraplegic Centres, is that five per cent of patients with dis z prolapse have bladder dsyfunction but this is only severe or permanent in two per cent. In other words, a fifth have bladder dysfunction if this is looked for, usually either irritability or some loss of sensation, and will be found to have abnormal urodynamic studies. Massive disc protrusions at the L5/SI level are the commonest site of disc paraplegia.

\section{Management of the Bladder in Spinal Degeneration}

The Uninhibited Bladder. If related to an acute disc prolapse it is likely to be transient and respond to manipulative treatment of the spinal lesion; in lumbar disc lesions bed rest or traction; in cervical spondylosis by a cervical collar. Presumably it results from nerve root irritation. Amitryptilline is of value and if there is an element of bladder or sphincter dyskinesia diazepam is effective in restoring the voiding pattern to normal.

Neuropathic Bladder with Retention. Most of these patients have a transient disturbance of bladder function so that catheter drainage is often only needed for a week. Sometimes the retention is related to enforced bed rest and possibly constipation which may too have a neurogenic cause. If the patient is then unable to void and there is no evidence of outflow obstruction carbachol or similar drugs may be tried but I have found little or no success with such measures. The outflow resistance can be reduced by surgery, preferably endoscopic, to the bladder neck or urethra.

Occult. To enable the bladder to completely empty endoscopic surgery is needed, for the weakened detrusor takes many months to recover and further damage by overdistension must be prevented. 
TABLE III

Management of vesical dysfunction in multiple sclerosis

\begin{tabular}{lrlr}
\multicolumn{3}{c}{ Men } & \multicolumn{1}{c}{ Women } \\
Medication alone & 2 & Medication alone & 3 \\
Incontinence devices or pads & 5 & Catheter or devices & 20 \\
Endoscopic surgery to & & Otis urethrotomy & 10 \\
$\quad$ external sphincter & IO & &
\end{tabular}

Disc Paraplegia. Again, surgery is needed to reduce outflow resistance to assist in complete evacuation as detrusor recovery is slow. The hazards of endoscopic surgery are less than those of long-term catheterisation and enable the patient to be discharged home.

\section{Multiple Sclerosis}

Just over half the patients with multiple sclerosis have multiple and persistent urinary symptoms which cause much social inconvenience. In some the urinary symptoms are transient and may improve, accounting for the fact that 78 per cent of multiple sclerosis patients have had urinary symptoms. Although these symptoms appear to cause much social inconvenience and rarely require hospital admission I2 per cent of 50 patients referred with urinary complaints died of renal causes in a five-year period. The causes of death were chronic pyelonephritis, three; amyloidosis, two; uraemia, one. During this period the only other death was due to bronchopneumonia in a tetraplegic with the disease.

Miller, Simpson and Yeates drew attention to the incidence of urinary tract disturbances in multiple sclerosis and our findings confirm their figures. I was surprised at the contribution urinary tract disease made to the mortality in this condition. Perhaps, as the majority of complaints may appear to be just socially embarrassing, it is easy to overlook the contribution renal disease makes to the overall mortality in multiple sclerosis.

The neurogenic incontinence in women is particularly disabling and many need an indwelling catheter (20/50 cases) for retention with overflow. However, where there is bladder-neck dyskinesia Otis urethrotomy (IO/50 cases) or, in men, division of the external sphincter (IO/50 cases), has been performed with good results. Whenever permanent catheterisation is needed great care must be taken to use urethral antiseptics and a small-calibre catheter to prevent septicaemia and urethral ulceration; a fine Gibbon balloon catheter is satisfactory provided vigilance is taken to prevent egg-shell calculus.

Where the main problem is of an uninhibited bladder with or without bladderneck dyskinesia, amitryptilline $10-20 \mathrm{mgm}$. t.d.s. or diazepam $10 \mathrm{mgm}$. t.d.s. is often helpful in reducing or eliminating the urge incontinence. Diazepam appears to have a selective effect upon the external sphincter and helps when intermittent retention has been a problem. Although we have found that alpha-blockers can deal with sphincter spasm the long-term effects of Dibenzylalline 20 mgm. t.d.s. therapy are unpleasant. However, where it is important to preserve male fertility and avoid surgical division of the external sphincter, with the risk of retrograde 


\title{
TABLE IV
}

\author{
Prolonged survival after development of spinal metastases \\ 5 cases Hodgkin's disease survived 5-10 years \\ 6 cases multiple myelomatosis survived 6-II years \\ 9 cases carcinoma of the prostate survived 5-10 years
}

ejaculation, Dibenzyalline could be used. However, this is an academic point for all men with multiple sclerosis and bladder-neck dyskinesia are impotent, whereas only a quarter of men with an irritable uninhibited bladder are impotent.

It is my belief that endoscopic division of the external sphincter has a part to play in the management of men with sphincter problems in multiple sclerosis; its low morbidity and mortality and freeing the patient from the need for a urinary appliance justify its use. Initially I was reluctant to advocate surgery in patients with multiple sclerosis as the disease has an unpredictable course, but I am now convinced that it has a small but definite contribution to make. The mainstay of management is in the selection of medication and appliances. I have found amitryptilline, diazepam and Imipramine the most useful drugs and have not found much success with Cetiprin (emepronium bromide) or probanthine. Absorbent underclothes with a replaceable marsupial pad (Kanga pants) are valuable for urinary or double incontinence and are often preferred by men in preference to a dribble bag for an intermittent urinary leak. A condom appliance connected to a plastic legbag urinal is a good method of drainage and, as most men have some sensation in the genitalia, problems due to penile ulceration and incorrect fitting are avoided. Incontinent women with the urge bladder are always difficult to treat. Some may find absorbent pants of limited help and ask for an indwelling catheter. A few with lax pelvic muscles and incontinence have been controlled with the Lyn Edwards pubo-vaginal device.

No hard and fast rules can be made, each individual must be considered as a whole. Theoretically one could do urodynamic studies and full urological investigations and prescribe an appliance, forgetting that patients with multiple sclerosis may have a marked tremor or inco-ordination preventing use of the appliance. In the field of neurological urology one can be lost in a maze of synapses and physiology and forget that a human being needs help.

\section{The Neurogenic Bladder in Malignant Disease}

Finally I wish to close on an optimistic note. Two years ago whilst preparing for the course I was surprised to find that certain paraplegic patients with malignant disease had not only a prolonged survival after the onset of paraplegia but could be rehabilitated (Jameson, 1974). When patients are found to have paraplegia, with malignant disease it is usually the death knell; however, in Hodgkin's disease, reticulo-endothelial malignancies, in prostatic and testicular tumours, survival is prolonged and the quality of life good, justifying vigorous rehabilitation which may include urological surgery. This is due to advantages of a multi-disciplinary approach in the treatment of malignant disease and to the good results from multiple chemotherapy. 


\section{SUMMARY}

The urological management in non-traumatic paraplegia differs little from the management of the traumatic case; a policy of conservative optimism is adopted, particularly in dealing with multiple sclerosis and certain malignancies.

\section{RÉSUMÉ}

Le traitement urologique dans les cas de paraplégie non-traumatique diffère peu du traitement appliqué aux cas traumatiques. On adopte la politique de l'optimisme prudent, en particulier dans le cas de la sclérose en plaques et pour certaines malignités.

\section{ZUSAMMENFASSUNG}

Die urologische Behandlung in nicht-traumatischer Paraplegie unterscheidet sich wenig von der Behandlung traumatischer Fälle. Eine Politik von konservativen Optimismus wird angenommen, insbesondere gegenüber Fällen von multiplier Sklerosie und gewissen Fällen von malignen Erkrankungen.

\section{REFERENCES}

Abel, B. J., Gibbon, N. O. K., Jameson, R. M. \& Krishnan, K. R. (1974). Lancet, I229. EMmetT, J. L. \& Love, J. G. (I968). F. Urology, 99, 597.

EMMETT, J. L. \& Love, J. G. (1971). F. Urology, 105, 86.

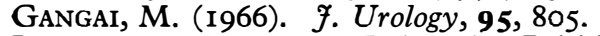

JONES, D. L. \& MOORE, T. (1973). British fournal of Urology, 45, 39.

JAMESON, R. M. (1974). Paraplegia, 12, 92.

JAMESON, R. M. (I974). Lancet, I, 209.

Love, J. G. \& Emmett, J. L. (I967). Proc. Staff Meeting Mayo Clinic, 42, 249.

MALLOCK, J. D. (1965). British Fournal of Urology, 37, 578.

Mayo, M. E., Lloyd-Davies, R. W., ShuttleWorth, K. E. D. \& Tighe, J. R. (I973). British Fournal of Urology, 45, I 6 .

Miller, H., Simpson, C. A. \& Yeates, W. K. J. (1965). British Medical Fournal, 1, 1265.

Ross, J. C., GibBon, N. O. K. \& Damanski, N. (I964). Lancet, 779.

Ross, J. C., JAMESON, R. M. (I97I). British Medical fournal, 3, 752.

YAXIEY, E. (1966). British fournal of Urology, 38, 324. 